\title{
APPLICATION OF A HEPARIN REMOVAL DEVICE IN PATIENTS WITH KNOWN PROTAMINE HYPERSENSITIVITY
}

Joseph B. Zwischenberger, MD, Roger A. Vertrees, BA, CCP, Robert L. Brunston, Jr., MD, Weike Tao, MD,

Scott K. Alpard, MD, and Paul S. Brown, Jr., MD, Galveston, Tex.

Severe life-threatening reactions have been reported in association with protamine use, including pulmonary hypertension, systemic hypotension, and anaphylactic shock, as well as thrombocytopenia, granulocytopenia, complement activation, and cytokine release. ${ }^{1}$ As an alternative to protamine administration, a heparin removal device (HRD, Research Medical Inc., Midvale, Utah) uses a venovenous extracorporeal circuit with plasma separation and poly-L-lysine affinity adsorption to remove heparin from the blood. ${ }^{2} \mathrm{We}^{3}$ previously reported the first compassionate clinical use of the HRD to decrease lifethreatening bleeding in a patient who could not tolerate protamine. Through large animal studies, $\mathrm{we}^{4-6}$ have since characterized the performance of the HRD and developed a heparin clearance mathematical model to determine the HRD run time needed for a targeted $90 \%$ heparin removal based on first-order exponential deple-

From the Department of Surgery, Division of Cardiothoracic Surgery, The University of Texas Medical Branch, Galveston, Tex.

Address for reprints: Joseph B. Zwischenberger, MD, Division of Cardiothoracic Surgery, 301 University Blvd., University of Texas Medical Branch, Galveston, TX 77555-0528.

J Thorac Cardiovasc Surg 1998;115:729-31

Copyright (C) 1998 by Mosby, Inc.

$0022-5223 / 98 \$ 5.00+0 \quad \mathbf{1 2 / 5 4 / 8 7 3 5 6}$ tion. Variables affecting the HRD efficiency, such as extracorporeal blood flow, sorbent amount, and cannula placement, have likewise been improved. The HRD returns activated clotting time (ACT) and other measured coagulation variables to near baseline values in approximately 30 minutes in adult-sized subjects at the venovenous extracorporeal blood flow rate of $1400 \mathrm{ml} / \mathrm{min}$ without any apparent adverse effects on hemodynamics. ${ }^{4-6}$

From May 6 to May 27, 1997, two patients scheduled for elective coronary artery bypass grafting had documented "hypersensitivity" to protamine, and the HRD was used as an alternative to reverse systemic heparin anticoagulation. Since the HRD has not been approved by the Food and Drug Administration, approval for compassionate use was obtained from the Institutional Review Board of the University of Texas Medical Branch, Galveston, Texas, and informed consent was obtained from each patient before the operation.

Because of persistent angina after a recent myocardial infarction, a 58-year-old woman underwent cardiac catheterization demonstrating severe three-vessel disease. On completion of her cardiac catheterization she was given protamine $(4 \mathrm{mg})$, resulting in dizziness, an urticarial eruption, and hypotension $(74 / 50 \mathrm{~mm} \mathrm{Hg})$. She was treated with intravenous antihistamines (Benadryl 100 $\mathrm{mg}$ ) and steroids (Solu-Medrol $125 \mathrm{mg}$ ) for a presumed protamine reaction. She continued to be hypotensive, despite treatment, and received $1.5 \mathrm{~L}$ of crystalloid solu- 


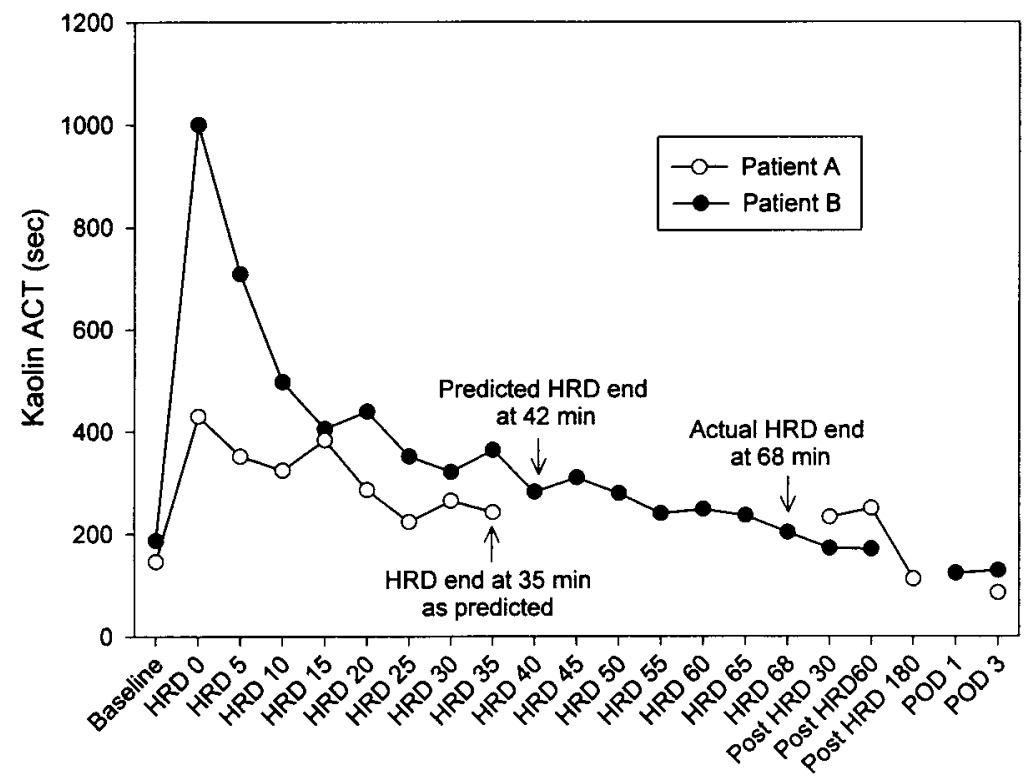

Fig. 1. ACT time course at baseline, during HRD, and after the operation.

tion and inotropic support. She recovered over 4 to 5 hours and was referred for revascularization. After threevessel coronary artery bypass grafting, the patient had good hemodynamics and was weaned from cardiopulmonary bypass (CPB). To avoid protamine, we used the HRD. The right atrial venous cannula was removed and the HRD dual-lumen venovenous cannula was inserted through the same atriotomy. The distal port was positioned into the inferior vena cava for drainage and the proximal port at the level of the right atrium for reinfusion, oriented toward the tricuspid valve to minimize blood recirculation. Blood flow was controlled by a roller pump that drained blood from the inferior vena cava and pumped it through the plasma separator, whose hollow fibers allow for plasmapheresis. The strongly negatively charged heparin binds with the strongly positively charged poly-L-lysine-agarose to remove heparin from the blood. The heparin-depleted plasma then reenters the hollow fibers to recombine with the formed elements of the blood and return to the patient's right atrium.

The HRD was used at a target flow rate of $1400 \mathrm{ml} / \mathrm{min}$ for 35 minutes as predicted by our mathematical model of first-order exponential depletion for a targeted $90 \%$ heparin removal. No changes in hemodynamics occurred during the use of the HRD. Heparinized pump blood (700 $\mathrm{ml}$ ) was infused via the aortic cannula to replace cardiotomy suction during the HRD run. Fig. 1 (patient A) shows the ACT time course at baseline, during the HRD run, and after the operation. Before and after the HRD run, fibrin degradation products were less than $5 \mu \mathrm{g} / \mathrm{ml}$, activated partial thromboplastin time greater than $150 \mathrm{sec}-$ onds, and d-dimer less than $0.5 \mathrm{ng} / \mathrm{ml}$. Platelet count was $225,000 \mu \mathrm{l}$ immediately after CPB, 167,000 $\mu \mathrm{l}$ after the HRD run, and 272,000 $\mu 13$ hours after the operation. The plasma free hemoglobin concentration was $19 \mathrm{mg} / \mathrm{dl}$ immediately after CPB, $25 \mathrm{mg} / \mathrm{dl}$ after the HRD run, and 3 $\mathrm{mg} / \mathrm{dl} 3$ hours after the operation. The hematocrit value showed typical changes related to $\mathrm{CPB}$ with hemodilution. The patient was transferred to the intensive care unit with chest tube drainage of only $300 \mathrm{ml}$ over the first 6 hours. No blood products including red blood cells, fresh frozen plasma, platelets, or clotting factors were given, and there was no evidence of significant bleeding or identifiable complications. She was ambulatory on postoperative day 3 , discharged day 5 , and is doing well 3 months after the operation.

A 63-year-old $(136 \mathrm{~kg})$ woman with a history of hypertension and insulin-dependent diabetes had left carotid endarterectomy and three-vessel coronary artery bypass grafting 7 years ago when profound hypotension and elevated pulmonary pressures developed immediately after protamine administration, requiring a right ventricular injection of $300 \mathrm{mg}$ of epinephrine. The patient recently began having symptoms of congestive heart failure resulting from critical aortic stenosis and recurrent coronary artery disease. She underwent aortic valve replacement, a single coronary artery bypass graft, and intraaortic balloon pump placement. She was weaned from CPB after two attempts. The HRD dual-lumen venovenous cannula was inserted as described, and HRD at a flow rate of $1400 \mathrm{ml} / \mathrm{min}$ was used for 68 minutes. A 42-minute HRD run time at $1400 \mathrm{ml} / \mathrm{min}$ was initially predicted by the mathematical model and in retrospect was sufficient; however, the HRD run was extended because of a perceived increase in ACT at 40 to 50 minutes. A total of $1800 \mathrm{ml}$ of heparinized pump blood was infused via the aortic cannula to replace cardiotomy suction. Fig. 1 (patient B) shows the time courses for ACT at baseline, during the HRD run, and after the operation. Before and after the HRD run, fibrin degradation products were $<5$ $\mu \mathrm{g} / \mathrm{ml}$ and $>5<20 \mu \mathrm{g} / \mathrm{ml}$, activated partial thrombo- 
plastin time was greater than 150 seconds, and d-dimer was less than $0.5 \mathrm{ng} / \mathrm{ml}$. Platelet count was $138,000 \mu \mathrm{l}$ immediately after CPB, 111,000 $\mu \mathrm{l}$ after the HRD run, and 105,000 $\mu \mathrm{l} 24$ hours after the operation. Plasma free hemoglobin concentration was $48 \mathrm{mg} / \mathrm{dl}$ immediately after CPB and $52 \mathrm{mg} / \mathrm{dl}$ after the HRD run. The patient was transferred to the intensive care unit with chest tube drainage of $1930 \mathrm{ml}$ over the first 24 hours after the operation $(1425 \mathrm{ml} / 6 \mathrm{hr})$. She required 5 units of red blood cells, $75 \mathrm{ml}$ of platelets, and 4 units of fresh frozen plasma. She recovered and has returned to full activity at 3 months' follow-up.

The HRD achieves predictable systemic heparin removal, without causing additional blood cell damage, in clinical situations in which protamine may be contraindicated. The HRD awaits clinical trials for approval as an investigational device.

\section{REFERENCES}

1. Weiler JM, Gellhaus MA, Carter JG, et al. A prospective study of the risk of an immediate adverse reaction to prota- mine sulfate during cardiopulmonary bypass surgery. J Allergy Clin Immunol 1990;85:713-9.

2. Vertrees RA, Zwischenberger JB, McRea JC, Tao W, Kurusz M, Conti VR. Reversal of anticoagulation without protamine using a heparin removal device after cardiopulmonary bypass. ASAIO J 1994;40:M560-4.

3. Conti VR, Vertrees RA, Zwischenberger JB, Kurusz M. First clinical use of a heparin removal device: an alternative to protamine. J Thorac Cardiovasc Surg 1995;109:1015-7.

4. Tao W, Callahan JD, Vertrees RA, Brunston RL Jr, Deyo DJ, McRea JC, et al. Heparin clearance profiles following systemic anticoagulation using a heparin removal device system. ASAIO J 1997;43:922-6.

5. Tao W, Deyo DJ, Brunston RL Jr, Vertrees RA, Grochoske TL, Zwischenberger JB. Extracorporeal heparin adsorption following cardiopulmonary bypass with a heparin removal device: an alternative to protamine. Crit Care Med. In press.

6. Tao W, Deyo DJ, Brunston RL Jr, Vertrees RA, Grochoske TL, Zweischenberger JB. Efficacy of a heparin removal device in comparison with protamine after hypothermic cardiopulmonary bypass. ASAIO J 1997;43:M825-30.

\section{Notice of correction}

In the February 1998 issue of the Journal, in the article by Gammie and associates titled "Single- Versus Double-Lung Transplantation for Pulmonary Hypertension" (1998;115:397403), an error was made. In Table III, the final three entries in the single-lung transplantation (SLT) column should have been placed in the double-lung transplantation (DLT) column. 